Hyderaly, H., Thayaparan, M. and Aarifkhan, F., 2019. The concept of value engineering and its assimilation in Sri Lankan construction industry: A literature review. In: Sandanayake, Y.G., Gunatilake, S. and Waidyasekara, A. (eds). Proceedings of the $8^{\text {th }}$ World Construction Symposium, Colombo, Sri Lanka, 8-10 November 2019, pp. 556-566. DOI: doi.org/10.31705/WCS.2019.55. Available at: https://2019.ciobwcs.com/papers

\title{
THE CONCEPT OF VALUE ENGINEERING AND ITS ASSIMILATION IN SRI LANKAN CONSTRUCTION INDUSTRY: A LITERATURE REVIEW
}

\author{
Hammadh Hyderaly' ${ }^{1}$ Menaha Thayaparan² and Fayasa Aarifkhan ${ }^{3}$
}

\begin{abstract}
Value is an ideational thought by which a worth of a good or service is expressed. Value Engineering is one of the tools used to evaluate such value and provide solutions for best fit value in real time. The core principle of practicing value engineering is to achieve value for money in construction projects, but it also bestows practitioners with added advantages such as innovative alternatives and enhanced quality. Even though value engineering is practiced globally, application of value engineering in Sri Lanka is highly limited due to lack of knowledge and awareness of the concept of value engineering, lack of realisation of the benefits it can bring to the construction projects and lack of government support. Hence, Sri Lankan construction industry lacks initiatives to pursue integration of value engineering in construction projects. The objective of this paper is to explore the idea behind the term "value" through value engineering and manifest previously identified causes and mitigation strategies to enhance value engineering practices within Sri Lanka. A comprehensive literature review has been carried out to disclose facts and cues of value engineering identified globally and to contextualise the concepts of value engineering within Sri Lankan construction industry. This paper emphasises that value engineering enhances the total value of the project while irradiating unnecessary costs associated with the projects. However, Sri Lankan construction industry is not practising value engineering in its full potential due to barriers identified above. Recommendations were, therefore, proposed to reveal the importance of standardising value engineering practice in Sri Lankan construction industry.
\end{abstract}

Keywords: Construction Industry; Value; Value Engineering; Value Management; Sri Lanka.

\section{INTRODUCTION}

Construction industry is evolving into seeking the need of value over cost (Rad and Yamini, 2016). Cost is an inevitable notion in construction industry whereas value is a concept by which such notion can be manipulated to best fit purpose (Dell'Isola, 1997). Mechanism of seeking value was developed in 1947 by Lawrence D. Miles in formulating an approach to reduce cost by a set of methodical functions and such technique was known to be value analysis (Kelly et al., 2015). Since such focus was given to value, it

\footnotetext{
${ }^{1}$ Department of Building Economics, University of Moratuwa, Sri Lanka, hammadh94@gmail.com

${ }^{2}$ Department of Building Economics, University of Moratuwa, Sri Lanka, mthayaparan@uom.lk

${ }^{3}$ Department of Building Economics, University of Moratuwa, Sri Lanka, aariffaya@gmail.com
} 
has been remained prominent in many industries and noteworthy in the case of construction industry (Kelly et al., 2015). Seeking value for a product in construction industry is generally initiated by client (Kelly and Duerk, 2002). They also stated that in such case, client would go through a system to define the needs and wants in an elaborated manner.

Value can be expressed through value for money (VFM), and in its entirety, opting for such change from analysis should not prevent the system from performing its basic predefined functions (Younker, 2003). VFM can be simply stated as worthiness of the investment on the project by client or optimal combination of quality, function and cost to meet the end clients' requirement, thus, bringing out meaning of value relative to the client (Kelly et al., 2015). VFM is being actively sought in construction sector due to its dynamic and risk prone environment (Ekanayake and Sandanayake, 2017). Value for Money (VFM) in construction is the optimum balance between managing costs without compromising on quality (Shaw, 2016). There are several mechanisms to obtain VFM in construction. Few to name are zero-based budgeting, target costing, benchmarking, total quality control, quality function deployment (Richard, 1998). Among these, value engineering (VE) has been considered as one of the best method for expressing VFM (Green, 1990; Chavan, 2013; Rad and Yamini, 2016).VE is defined 'as the process of analysing the functional benefits a client requires from the whole or parts of the design' (Potts, 2008, p.92; Potts and Ankrah, 2013). VE stands out to be an exceptional value seeking technique as it emphases on elevating quality of construction elements through creativity of professionals by focussing on the functions of such element when compared to other existing mechanisms in the construction industry (Rad and Yamini, 2016). VE is also identified as a procedural value enhancing management mechanism which is applied into a construction project (Male et al., 2007).

However, regardless of the merits expressed and implied by practicing VE, its application in Sri Lanka is highly limited (Karunasena and Gamage, 2017). VE is not been explicitly identified by previous studies within Sri Lanka. Importance of VE relies on global reference of VE being a better value seeking mechanism, thus, such practice could be followed in Sri Lanka to enhance the products of construction industry. Also, since there is no standardised procedure to seek value rich construction projects in Sri Lanka, VE would be a best fit technique to achieve such project which subsequently would enhance better economic output of Sri Lankan construction industry. Commonly identified reasons for drawbacks in practicing VE in Sri Lanka were lack of awareness of VE and its application among personnel in construction industry, vagueness of the results derived from such analysis, shortcomings in the extended support by government or governing bodies, extra cost involved when performing VE and formalising into a report, increased time duration to conduct analysis, unavailability of proper expertise and absence of rules and regulations to such practice in construction industry (Karunasena and Gamage, 2017).

Even though the benefits of practising VE are understood, it is mainly due the barriers mentioned above, the VE is not considered as a feasible option to be implemented in Sri Lankan construction industry. There is currently a dearth of research conducted to analyse the significance of VE for Sri Lankan construction industry. There have been no projects in Sri Lanka where the VE has been performed with its full potential. As Sri Lankan construction industry is developing with increased number of major scale projects with foreign investments, it is now the high time for the industry to adopt VE practices. Hence, a study is required to address research gaps associated with VE practices in Sri Lankan 
construction industry. In this context, this paper presents an in-depth literature review on the aspects of understanding the term 'value' and 'VFM' in order to emphasise the significance of VE in achieving VFM. It also explores the optimal stages to establish VE in a construction project, merits and demerits of VE practices in Sri Lanka and the reasons why such practices were not standardised. The paper also proposes the necessary recommendations to enhance VE practices in Sri Lankan context.

\section{METHODOLOGY}

The objectives of the paper are to explore the concepts of value, value for money and value engineering, VE practices with their merits and demerits and barriers of practicing $\mathrm{VE}$ in construction industry. These objectives were achieved through a comprehensive literature review associated with VE concepts and its applications. The analysis was streamlined to depict aforementioned details in the context of Sri Lankan construction industry. However, there is a dearth of research and reporting on VE within Sri Lankan construction industry in comparison to global frame of reference. Thus, literature claiming VE as one of the best value seeking mechanisms in global context was reviewed and critiqued to determine the suitability of VE practices in Sri Lankan construction industry and to propose some recommendations to enhance VE with the support of above mentioned sources. The next section reviews the literature that explores the concepts of value and value seeking mechanism, merits and demerits of VE, barriers of practicing VE in construction industry, followed by key recommendations to enhance the VE applications in Sri Lankan construction industry.

\section{LITERATURE SYNTHESIS}

\subsection{Value and Value Seeking Mechanisms in Construction INDUSTRY}

"Value is a measure expressed in currency, effort, exchange or on a comparative scale, which reflects the desire to obtain or retain an item, service or ideal" (Kelly and Male, 2005 , p. 9). Potts (2008, p.92) defined that value is the level of importance that is placed upon a function, item or solution. Value can be stated under four economic values, such as esteem value, exchange value, use value and cost value (Mukhopadhyaya, 2009). It is further stated that esteem value is a driving force which would lead a person or organisation to pursue on selected item of interest, exchange value is worth of an object or service which is used as a base for interchange, use value defines the nature of the purpose which was used to create the commodity and cost value encompasses all cost from the beginning to the final disposal of a product or service. But, when focussed on value in construction industry, it can be stated as a network of all performance indicators including the traditional indicators such as time, cost and quality and emerging indicators which comprises of client satisfaction, environmental impact and sustainability (Oke and Aigbavboa, 2017).

Concept of value incorporates many characteristics, such as, objective, subjective, relative, context dependent and dynamic (Salvatierra-Garrido and Pasquire, 2011). Dell'Isola (1997) expresses value as the most cost effective way to meet clients' or users' needs and wants through a derivative which is met by using a desirable function. Furthermore, he also specified that value can be explained as shown in equation (01). 


$$
\text { Value }=\frac{\text { function }+ \text { quality }}{\text { cost }}
$$

Where, function $=$ the specific work that a design or item must perform, quality $=$ the owner's or user's needs, desires and expectations, and cost $=$ the life cycle cost of the product.

However, the above stated mathematical function could not be directly applied to gain the end result of "value", but merely to understand its concept. The are several alternative techniques such as zero-based budgeting, target costing, benchmarking, total quality control, quality function deployment, failure mode and effect analysis, design for assembly and value management etc. (Richard, 1998) to achieve VFM in the construction industry. Rad and Yamini (2016), after comparing 15 such alternatives across 20 systems such as budget control, creating new ideas, improving quality and function etc. using a 5scale method, concluded VE has been scored the highest indicating it is the most suitable option to achieve VFM in construction management.

\subsection{VALUE ENGINEERING AND ITS APPLICATIONS}

Value management is a process whereby the project is evaluated and scrutinised to obtain maximum value for money by following a prescribed methodology (Olawumi et al., 2016, p.40) where VE is one key phase that is undertaken in the process of value management. VE is an integral part of value management which is diversified into value planning, value analysis, value control, value methodology, value improvement, and value assurance (Oke and Aigbavboa, 2017). They also stated that VE is the aim and definition of value management. VE is not only applied in construction industry but also in manufacturing industries (Mukhopadhyaya, 2009). Potts (2008) identifies VE as a phase in the whole value process of value management, where it is also closely connected to value planning and value reviewing as other stages of value management. Figure 1 indicates interactions between value planning, value engineering and value reviewing and means by which these are achieved.

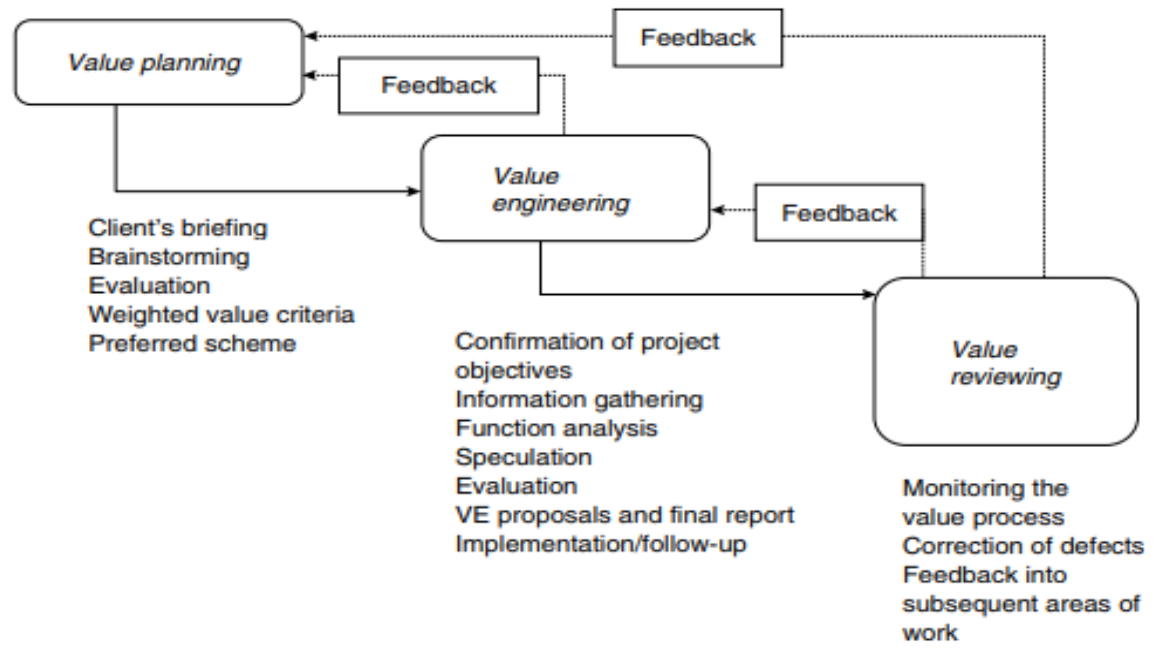

Figure 1: Process of value management (Source: Institute of Civil Engineers, 1996)

VE perceives to achieve VFM by allowing all indispensable functions to be accomplished with lower total cost through a systematic technique (Male et al., 2007). It was deduced by Chavan (2013) that VE is one of the most appropriate systematic approaches to seek 
a better value in construction projects and to elevate the options in a standard manner. $\mathrm{VE}$, in general targets to obtain better functionality of construction projects at the least possible cost. Zhang et al. (2009) identified VE as a management tool, which is used in achieving essential functions of a product, service or project with a lowest cost, whereas Male et al. (2007) mentioned VE as a methodological value enhancing management style.

The concept of VE is also perceived as a systematised application which combines the idea of technical knowledge along with common sense to find potential situations or method of executions where cost for such can be deduced unnecessary and eliminates such cost which subsequently leads to better VFM (Chen et al., 2010). Process of VE would reveal constructability, manufacturability and maintainability of an ongoing or proposed project at early stages of its execution, hence suggests solutions or mitigation strategies for forthcoming problems (Nawi et al., 2014).

$\mathrm{VE}$ is one of the best fit practice for regulating a better value in construction projects as other techniques lean on the prime focus of quality and time than VFM (Zhang et al., 2009; Rad and Yamini, 2016; Oke and Aigbavboa, 2017). Furthermore, Ellis et al. (2005) mentioned that VE is a system which induces creativity, innovative ideas, alternative solutions, and generally indulge in some 'out-of-the box' thinking in introducing proper changes to the construction procedures. The basis of VE is not a standalone cost cutting technique, but it plays the role of analysing, evaluating and reporting best valued approaches or in simpler terms triangulates a better VFM for a project (Perera et al., 2011). VE is classified as a disciplined methodology and a ground which utilizes creativity to provide the client with reliable alternatives for cost saving purposes by negating deleterious outcomes on performance and quality (National Research Council, 2009). VE can be applied in multitude of stages in construction as shown in Figure 2.

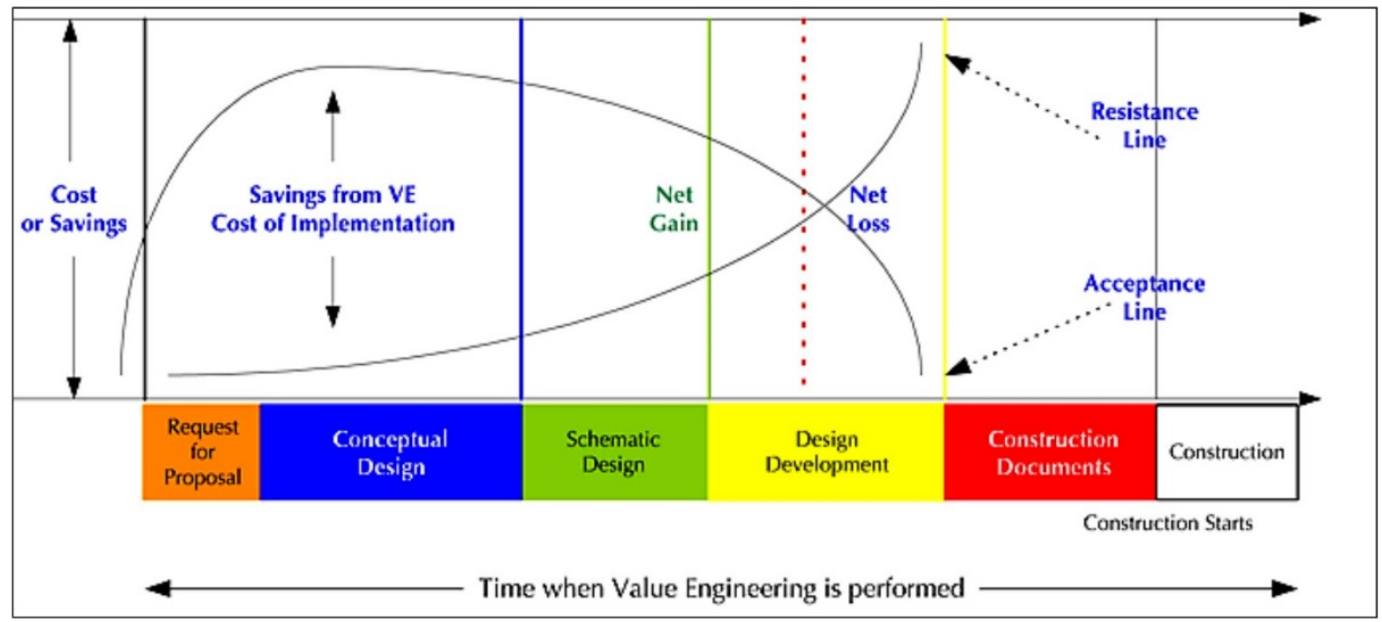

Figure 2: Application of VE in stages of construction (Source: Rad and Yamini, 2016)

Figure 2 clearly shows that VE triggers maximum cost savings only when applied during conceptual design stage mainly due to flexibility of choosing alternatives and diversified options available to express VFM. In agreement to this view, Potts and Ankrah (2013) argues cost reduction potential is high at the initial stages of a project as the opportunities for making changes will tend to reduce as the project progress with an increased cost to such changes at later stages. Conversely, when such practice is executed in latter stages like design development, it creates excessive resistance to choose and as a result could reduce the potential savings or incur cost in the perspective of value. This phenomenon 
is due to the fact that early stages of construction projects being susceptible to change as a result, could be advantageous to find proper alternatives without significantly harming the progress of construction (Yin et al., 2016). Since value engineering is not explicitly realised to be a best fit value attaining standard in Sri Lanka, application of such system is much linear and selective (Kosala and Karunasena, 2015).

\subsection{MERITS AND DEMERITS OF VALUE ENGINEERING}

A proper establishment of VE could reap many advantages. The basis of VE starts with a brainstorming session which incorporates ideas of many who are involved in the project (Norton and McElligot, 1995; Connaughton and Green, 1996; Younker, 2003; Potts, 2008; Mukhopadhyaya, 2009; Potts and Ankrah, 2013). Whilst the contribution of every personnel involved in a project reaches the common goal of finding VFM, the coordination between parties to be elevated to much further level to reach the VE objectives (Connaughton and Green, 1996; Kelly et al., 2015). The brainstorming also contributes towards effectively working in a team based environment with less difference of opinions. Such coordination also encourages all personnel to ruminate in diversified ways, in simpler terms, "out-of-the-box" thinking is much motivated among the personnel. This thinking process leads to increased innovation on delivering the best fit product or alternative within the project and elevates alternative seeking capabilities. Subsequently, it paves the way towards elimination of unnecessary cost associated with the project, which happened to be part of it prior to VE initiatives (Norton and McElligot, 1995; Connaughton and Green, 1996). This does not dictate that VE only relinquishes cost related to the face values of a project, but it also analyses the total life cycle cost of a component to deliver best VFM (Norton and McElligot, 1995; Kosala and Karunasena, 2015). It is further stated that however, by doing so, parties of the construction project are able to detect and seek remedies for deficiencies and eradicate superfluous items in the initial scope of construction.

VE applied on a construction project, reviews the whole of project than a specified element or set of elements (Dell'Isola, 1997; Potts, 2008; Kelly et al., 2015). Hence, brings about multitude of value rich aspects within a project. As VE is a process which details features of a project, it focuses even on a miniscule detail, refining the status quo and identifying project constraints which would not otherwise have been encountered (Norton and McElligot, 1995). Furthermore, such actions result in management of the project to take key decisions which are derived from the nature of arriving to alternatives of best value. At critical stages, such decision would immensely prove beneficial to the project itself. Periodically, when following VE practices, an organization could identify and prioritise needs to deliver optimal VE results within specific frame of time to aid the most concerned party (Norton and McElligot, 1995; Connaughton and Green, 1996). Subsequently, through effective practice of VE initiatives, it paves the way to maximum return on minimal investment (Norton and McElligot, 1995; Dell'Isola, 1997; Younker, 2003; Kelly and Male, 2005).

However, VE practices is not always perceived to be universally advantages. It also carries certain disadvantages when applied into a project. As stated above, VE initially starts with a brainstorming session. Even though this action divulges great concerns on the project, it could also lead to confrontational arguments between parties of the construction project (Kelly and Male, 2005; Kelly et al., 2015). This subsequently could result in development of a communication barrier between stakeholders of the project. 
Moreover, using the internal design team in VE study can be time and cost saving as the internal group has been already identified and payments could be negotiated in a positive manner. However, it is considered rather suboptimal because of the fact that ideas generated from internal design team is brought forward to be agreed upon, any changes in such design could generate resistance for such team as they would hesitate to contemplate their own ideas and creativity (Norton and McElligot, 1995; Kelly and Male, 2005). VE can also be initiated with outsourcing VE application to an external entity comprising of personnel skilful in value management, but this could incur additional cost to the project. It is mainly due to the fact that VE generally saves more than $10 \%$ of the project cost, thus payment requirement of personnel would not be less than such margin of potential savings (Norton and McElligot, 1995). An effective VE also consumes time due to its nature of elaborative study which in critical situations could be a roadblock to the entire project (Potts, 2008). Effective application of VE could reap the aforementioned benefits, but due to certain barriers, the full potential of VE is not generally observed in the construction industry.

\subsection{Barriers to Value Engineering Practices in Construction INDUSTRY}

Lack of support extended by government in incorporating VE or value management policy in standards of the construction industry is a prime reason for lack of widespread use of VE within Sri Lanka (Kosala and Karunasena, 2015; Oke and Aigbavboa, 2017). If initiatives are taken through a regulating body such as Construction Industry Development Authority (CIDA) by providing guidelines to the use of professionals from the construction industry, VE could be made into a mandatory standard. Further, shortcoming in knowledge on VE and value management also is a contributing factor for its unpopularity ( $\operatorname{Rad}$ and Yamini, 2016). Restricted practice of VE arises due to said reasons, which consequently could reduce stakeholders' interest on considering VE as an option. Creating awareness among stakeholders could minimise the restrictions on VE practices in practical execution of the project (Xiaoyong and Wendi, 2012; Oke and Aghimien, 2018). It is much suited if such social awareness is detailed with benefits to all the construction industry practitioners, especially client. Presenting sentience on VE to the client is most crucial, as client is the drive force of a project and elevated importance and involvement of client in VE practice could prove to its acceptance in construction industry (Oke and Aigbavboa, 2017). Absence of an induction programme within an organization is also a barrier for practicing VE as organisation itself is not keen on incorporating VE practices (Xiaoyong and Wendi, 2012). Drawback of VE in electronic medium, i.e. as a computer aided programme, can be a major setback as almost every operation in construction industry is revolutionised with support by information technology systems (Oke and Aigbavboa, 2017).

However, in Sri Lankan context, VE is often perceived in the form of proposal submitted by the contractor during project execution, where contractor aims to achieve hidden benefits along with delivering the work for lesser cost with reduced time (Kosala and Karunasena, 2015). Implementation of alternatives derived from VE practices generally depend on the experience and expertise of the stakeholders in a project (Karunasena and Gamage, 2017). Furthermore, it was also disclosed that VE practices are executed as per the project stakeholders to correspond with the project. Also, a common misconception in Sri Lanka is that VE is performed only on the basis of reducing the face value of the 
cost, whereas in reality it evaluates and analyses all cost related elements from inception to disposal of a project. It clearly indicates that the VE are not practised with its full potential in Sri Lankan construction industry. Hence, the benefits of VE practice discussed previously are not fully realised.

\subsection{RECOMMENDATIONS TO ENHANCE VE PRACTICES IN SRI LANKAN CONSTRUCTION INDUSTRY}

Value is a measure of worth which is constantly sought by human beings. The clients of Sri Lankan construction are no exception to this scenario. However, there is no defined technique in Sri Lanka to achieve VFM in building constructions. The literature review confirms that VE is a mechanism that has proven advantages in global context of construction industry. The literature further indicates that the VE is one of the best value seeking mechanisms and has a potential of being practiced while executing construction projects. However, VE practices are seldom recognized in Sri Lankan context. Lack of awareness, poor realisation of benefits, inability of the government to extend support and unavailability of proper expertise are some of the reasons why VE has not been popular in Sri Lankan construction industry. This section, therefore, discusses the recommended practices to enhance VE practices.

As a standalone organisation in construction industry, many changes could be made into one of organizations' practice on VE techniques which could disperse rapidly due to the merits of such work (Kosala and Karunasena, 2015; Karunasena and Gamage, 2017). One best recommendation is that each organisation should conduct an induction or training programme on VE among workers of the firm (Xiaoyong and Wendi, 2012; Oke and Aghimien, 2018). This training would greatly enhance future practices of VE. Following an accepted brainstorming session in a VE analysis is of due importance because, this action could reduce confrontation, arguments and could act as a knowledge pool since every member would be given an equal opportunity to express their own concerns (Norton and McElligot, 1995; Kelly and Male, 2005). In order to adopt VE practices in Sri Lankan construction industry, the industry practitioners can be motivated by providing incentives (Younker, 2003). Diversifying knowledge base through awareness by educating client should also be made to encourage the increased use of VE in selected projects. Provision of extended support by felicitating units which practice and execute VE in construction projects could act as a driver for other members of the organisation to follow such practices (Kosala and Karunasena, 2015; Karunasena and Gamage, 2017; Oke and Aghimien, 2018). Integrating a VE expert into a design team could significantly progress an entity towards following VE practices and its importance in construction projects. This could also pave the way to seek alternatives during design development stage which can later be made a standard in the practicing organization (Kelly et al., 2015).

Initiating changes within organization is in fact an effective principle. But, to make a major overhaul in the construction industry, it is necessary for the government or governing body to make the change. In such trend, regulating VE using construction law would make VE to be followed mandatorily when executing construction projects (Xiaoyong and Wendi, 2012; Oke and Aghimien, 2018). Increased government support in the form of tax incentives and reduced constraints for projects that practice VE would act as a driving force to follow VE practices by teams which do not usually follow such standards (Kosala and Karunasena, 2015; Karunasena and Gamage, 2017). Further, the 
contribution that can be provided by governing bodies such as CIDA should be emphasised to enhance the VE practices. CIDA as a governing body of construction can easily influence the professionals of the industry, as such it will be an ideal hub though which awareness and importance of VE can be disseminated. Incorporating VE related clauses into binding contracts between stakeholders will also help to improve the application of VE in construction.

\section{CONCLUSIONS}

Value is an often actively sought commodity in day-to-day life. However, parameters of value within construction industry dictates terms so that maximised VFM can be obtained through proper value seeking practices. Such trend led to execution of VE in the construction industry as VE proved to be the best fit technique to find VFM. Analysis and alternatives approach derived from VE during the pre-construction stage leads to maximum cost saving with much flexibility to choose without compromising quality whereas VE during construction could lead to additional cost and in some cases would act as a roadblock for construction projects.

It is conspicuous that VE and its practices are highly limited in Sri Lankan construction industry. Although construction projects are executed with certain degree of value seeking mechanisms, it lacks standardised practice of the most acclaimed technique. Factors such as lack of regulatory body or government support and lack of awareness of VE techniques among construction industry personnel has led to curtailment of VE application and practices. However, if involvement and dedication of client in seeking VFM is realised by either parties i.e. consultant or contractor, initiatives taken by client could lead to improved practice of VE. Hence, a value rich product can be delivered by cohesion of VE techniques in construction industry especially during design development stage of a construction project. As such this paper concludes that the VE practices are evidently limited in Sri Lankan construction industry mainly due to lack of knowledge, awareness and expertise among the professionals, lack of realisation of the benefits and lack of support from government or other relevant authorities. Increasing awareness and expertise on VE through training and education and encourage the government to support VE practices were the key recommendations proposed to address these barriers. As a way forward of this on-going research primary data have been collected from the industry practitioners who have either possessing the relevant knowledge or practising some form of VE. The primary data finding will be provided in subsequent publications.

\section{REFERENCES}

Chavan, A., 2013. Value engineering in construction industry. International Journal of Application or Innovation in Engineering and Management, 2(12), pp.18-26.

Chen, W., Chang, P. and Huang, Y., 2010. Assessing the overall performance of value engineering workshops for construction projects. International Journal of Project Management, 28(5), pp.514-527.

Connaughton, J. N. and Green, S. D., 1996. Value Management in Construction: A Client's Guide. London: Construction Industry Research and Information Association.

Dell'Isola, A., 1997. Value Engineering: Practical Applications for Design, Construction, Maintenance and Operations. Kingston: RSMeans.

Kelly, J. and Duerk, D., 2002. Construction project briefing/architectural programming. Best value in construction, pp.38-58.

Ekanayake, E. and Sandanayake, Y., 2017. LiVE approach: lean integrated value engineering for construction industry. Built Environment Project and Asset Management, 7(5), pp.518-533. 
Ellis, R., Wood, G. and Keel, D., 2005. Value management practices of leading UK cost consultants. Construction Management and Economics., 23(5), pp.483-493.

Green, S., 1990. The essentials of value engineering. Facilities, 8(10), pp.15-17.

Gudem, M., Steinert, M., Welo, T. and Leifer, L., 2013. Redefining customer value in lean product development design projects. Journal of Engineering, Design and Technology, 11(1), pp.71-89.

Institute of Civil Engineers, 1996. Creating Value in Engineering - Design and Practice Guide. London: Thomas Telford.

Karunasena, G. and Gamage, K. R., 2017. A decision-making formula for value engineering applications in. Journal of Financial Management of Property and Construction, 22(1), pp.77-91.

Kelly, J. and Male, S., 2005. Value Management in Design and Construction: The Economic Management of Projects. London: E. \& F.N. Spon.

Kelly, J., Male, S. and Graham, D., 2015. Value Management of Construction Projects. 2nd ed. West Sussex: John Wiley \& Sons.

Kosala, R.G. and Karunasena, G., 2015, August. Value engineering practices and its impact to construction industry. In Proceeding of the $4^{\text {th }}$ World Construction Symposium 2015: Sustainable Development in the Built Environment: Green Growth and Innovative Directions (pp. 538-546).

Male, S., Gronqvist, M., Kelly, J. and Graham, D., 2007. Managing value as a management. International Journal of Project Management, 25(2), pp.107-114.

Mukhopadhyaya, A.K., 2009. Value Engineering Mastermind from Concept to Value Engineering Certification. New Delhi: Sage Publications.

National Research Council, 2009. Advancing the competitiveness and efficiency of the U.S. construction industry, Washington, DC: The National Academies Press.

Nawi, M.M., Jalaluddin, S.M.F.W.S., Zulhumadi, F., Ibrahim, J.A. and Baharum, F., 2014. A strategy for improving construction projects sustainability through value management approach. International Journal of Applied Engineering Research, 9(24), pp.28377-28385.

Norton, B. R. and McElligot, W. C., 1995. Value Management in Construction: A Practical Guide. London: Macmillan.

Oke, A.E. and Aghimien, D.O., 2018. Drivers of value management in the Nigerian construction industry. Journal of Engineering, Design and Technology, 16(2), pp.270-284.

Oke, A. E. and Aigbavboa, C. O., 2017. Sustainable Value Management for Construction Projects. Cham: Springer International.

Olawumi, T.O., Akinrata, B.E. and Arijeloye, B.T., 2016. Value Management - Creating Functional Value for Construction Project: An Exploratory Study. World Scientific News, 54, pp.40-59.

Park, R., 1998. Value Engineering: A Plan for Invention. New York: CRC press.

Perera, S., Hayles, C. and Kerlin, S., 2011. An analysis of value management in practice: The case of Northern Ireland's construction industry. Journal of Financial Management of Property and Construction., 16(2), pp.94-110.

Potts, K., 2008. Construction Cost Management. Oxon: Taylor \& Francis.

Potts, K. and Ankrah, N., 2013. Construction Cost Management: Learning from Case Studies. $2^{\text {nd }}$ ed. Oxon: Taylor and Francis.

Rad, K. M. and Yamini, O. A., 2016. The Methodology of Using Value Engineering in Construction Projects Management. Civil Engineering Journal, 2(6), pp.262-269.

Salvatierra-Garrido, J. and Pasquire, C., 2011. Value Theory in Lean Construction. Journal of Financial Management of Property and Construction, 16(1), pp.8-18.

Shaw, J., 2016. Value Management vs Value Engineering. [Online] Available at: https://www.fgould.com/uk-europe/articles/value-management-vs-value-engineering/ [Accessed 23 August 2019]

Xiaoyong, L. and Wendi, M., 2012. Appraisal of Value Engineering Application to Construction Industry in China. Future Wireless Networks and Information Systems, 144, pp.303-311.

Yin, H.-W., Yang, H.-J. and Gao, H.-J., 2016. Analysis on Cost Management Application of Value Engineering at Design Phase of Real Estate Projects. Paris, Atlantis Press, pp.361-371. 
Hammadh Hyderaly, Menaha Thayaparan and Fayasa Aarifkhan

Younker, D. L., 2003. Value Engineering Analysis and Methodology. New York: Marcel Dekker, Inc.

Zhang, X., Mao, X. and Abourizk, S., 2009. Developing a knowledge management system for improved value engineering practices in the construction industry. Automation in Construction, 18(6), pp.777789 